\title{
IMPLEMENTAÇÃO DE FERRAMENTA PARA MODELAGEM DA DiNÂMICA DE Veículos de ESTEIRA EM AMBIENTE MULTiCORPOS
}

\author{
Nathan Mezacasa ${ }^{1.2}$, Rogério José Marczak ${ }^{1}$ \\ ${ }^{1}$ Universidade Federal do Rio Grande do Sul (UFRGS) \\ ${ }^{2}$ Faculdade da Serra Gaúcha (FSG) \\ E-mails: nathan.mezacasa@gmail.com, rato@mecanica.ufrgs.br
}

\section{RESUMO}

Este trabalho apresenta o desenvolvimento e implementação de uma ferramenta numérica, com o objetivo de simular a dinâmica de um veículo de esteiras, rodando em situações de operação extrema. Para tanto, todas as equações dinâmicas do problema foram obtidas e posteriormente programadas em software comercial. O software por sua vez, excita o modelo do veículo a partir do perfil do terreno, fornecido pelo usuário, calculando acelerações, velocidades, deslocamentos e forças, tanto rotacionais quanto translacionais, para cada grau de liberdade das massas suspensas e não suspensas do veículo. Para o desenvolvimento da esteira utilizou-se um modelo matemático que considera uma pré- tensão aplicada na sua montagem e a tensão dos vãos entre rodas como molas lineares exercendo uma força de restauração para alinhar estas rodas. Os resultados de simulações numéricas sob a forma de cursos de deslocamento de pontos característicos do casco e deslocamentos dos eixos de rodas em um sistema de coordenadas de referência assumido também estão incluídos.

\section{INTRODUÇÃO}

A necessidade de melhorar as capacidades de desempenho de veículos com esteiras forçou designers e engenheiros a encontrar uma maneira de lidar com esta tarefa de forma adequada e econômica. Durante muito tempo, o empirismo e a metodologia de testes em protótipos físicos foi a única técnica que poderia ser aplicada no desenvolvimento de veículos. À medida que a tecnologia do veículo se torna mais sofisticada e com uma procura crescente de maior mobilidade numa vasta gama de terrenos, esta abordagem tornou-se ineficiente e proibitivamente caro. Tornou-se necessário então, aplicar técnicas modernas de computador, matemática aplicada e mecânica dos solos na modelagem de veículos com esteiras.

Para solução de itens como estabilidade, performance em ride, e manobrabilidade, para veículos de esteira de alto rendimento, tais como tanques, modelos de análise numérica, os quais reproduzem matematicamente o movimento do veículo, são hoje tão importantes quanto testes, estes normalmente utilizados para validação final dos modelos numéricos. A importância do desenvolvimento desses modelos dinâmicos se dá, pois, a performance de veículos de esteira é normalmente afetada pela tolerância dos operadores às baixas frequências de vibração desenvolvidas pela interação das esteiras com o solo, sendo transmitida a suspensão, que por sua vez transmite ao casco. 
Percebe-se então que o sistema de suspensão destes veículos desempenha papel fundamental na redução da vibração resultante de excitações provenientes do solo, sentida pelos ocupantes, o que acarreta melhoria no conforto dos passageiros e maior estabilidade devido a elevada aderência das esteiras ao solo $[4,8]$.

Obter esses modelos dinâmicos antecipadamente permite predizer o comportamento da suspensão antes da sua construção, permitindo sua otimização, bem como o dimensionamento prévio de seus componentes. Desta forma, podem ser minimizados os custos de desenvolvimento do veículo, bem como reduzido o tempo para sua utilização em campo, devido a antecipação dos possíveis problemas que só seriam detectados nos testes do protótipo físico.

O presente trabalho objetiva o desenvolvimento e implementação de modelos dinâmicos para um veículo com esteira com a ação da pré tensão da esteira bem como sua rigidez. O modelo é equacionado para um veículo considerando suas massas suspensa e não suspensa. A esteira é considerada através de molas lineares e deslocamentos relativos das rodas próximas.

O equacionamento leva em conta a dinâmica vertical do veículo, considerando também efeitos de descolamento das rodas do terreno e os efeitos da esteira, algo raramente considerado na literatura. A solução das equações diferenciais do movimento do problema é realizada numericamente através de diagramas de blocos em um programa comercial [9].

Seguindo trabalhos similares, criou-se então um modelo cujo funcionamento é baseado na excitação da estrutura do tanque pela base, usando como sinal a amplitude do terreno variando no tempo.

Dhir \& Sankar [1] apresentam um modelo não-linear de um veículo de esteira de alta mobilidade para análise dinâmica de suspensão e avaliação de qualidade de rodagem. Foram realizadas análises comparativas entre quatro modelos matemáticos que representam a esteira através da avaliação de acelerações e frequências.

Gillespie [2] apresenta uma revisão do estado da arte da dinâmica de veículos em geral, definindo importantes conceitos que devem ser observados nos estudos de dinâmica veicular.

Lessem \& murphy [3] comparam diversos veículos militares com e sem esteira, a fim de entender as diferenças na dinâmica, com o objetivo de obter um modelo matemático capaz de predizer o comportamento de veículos de esteira em situações habituais e extremas.

Ravishankar \& Sujatha [5] estudaram um veículo militar sobre esteiras com 7 eixos e com suspensões passivas e independentes. Avaliou-se a aceleração vertical do CG e a aceleração angular do chassi para diferentes valores de rigidez da suspensão e diferentes perfis de terreno.

Wong $[6,7]$ apresenta uma breve revisão do estado da arte da dinâmica de um veículo de esteira, incluindo a mobilidade em terrenos macios, dinâmicas de passeio sobre superfícies irregulares e manobrabilidade. 


\section{MODELO MATEMÁTICO DE VEÍCULO DE ESTEIRA}

1.1. Considerações sobre dinâmica de veículos de esteira

Para proposta deste estudo, um modelo matemático de um veículo de esteira de $2+\mathrm{N}$ graus de liberdade, onde $\mathrm{N}$ é o número de rodas, foi modelado. $\mathrm{O}$ modelo utilizado é bidimensional, tendo além dos 6 graus de liberdade das rodas, os graus de liberdade de do deslocamento vertical e arfagem. A figura 1 apresenta o modelo de $1 / 2$ veículo com 8 graus de liberdade a ser estudado.

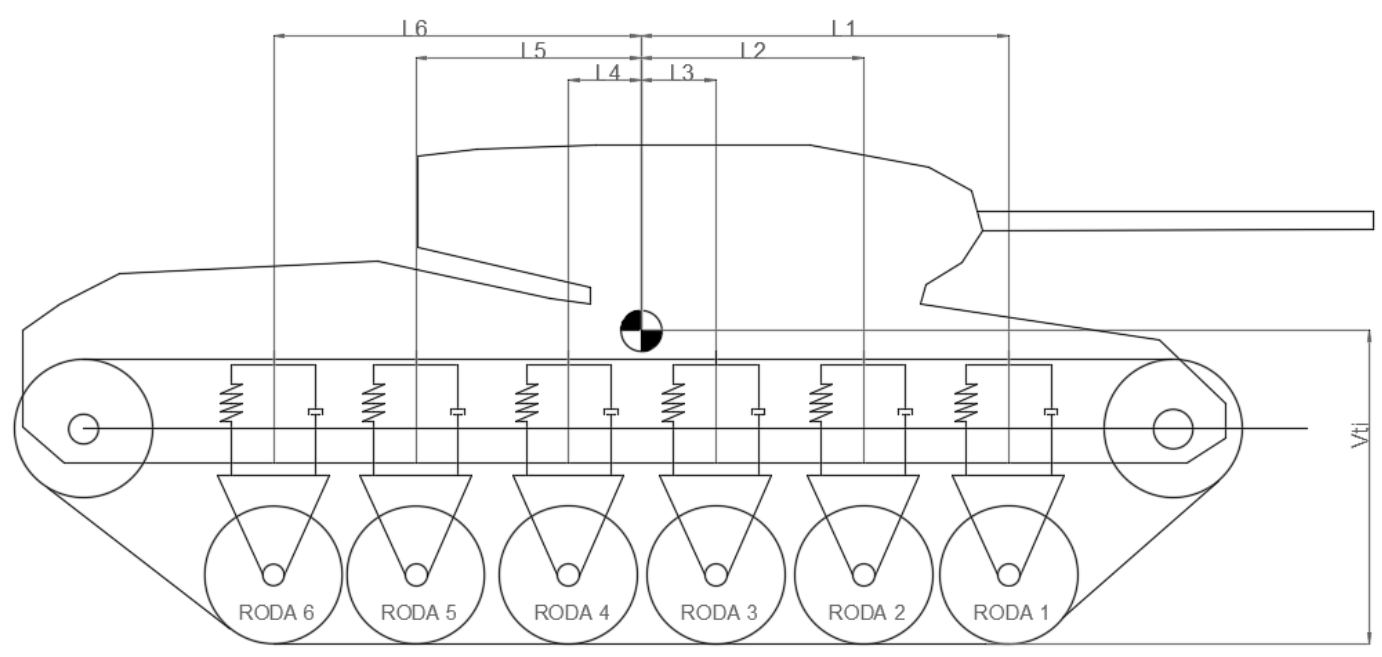

Figura 1 - Modelo de veículo com esteiras

A suspensão é idealizada como independente incorporando os efeitos de molas e amortecedores. Cada roda de rodagem é representada por uma mola radial contínua. $\mathrm{O}$ perfil de terreno aplicado para a o desenvolvimento das análises é assumido como não deformável.

As equações dinâmicas que governam os movimentos verticais e de rotação do casco e o movimento vertical das rodas são descritas baseadas na segunda lei de Newton de movimento.

Para a utilização deste modelo considera-se que a distribuição de massa e a geometria do veículo são simétricos ao eixo de rolagem do veículo, ou seja, possui igual distribuição entre os lados direito e esquerdo.

Por considerar o modelo do veículo como um corpo rígido, fica evidente que há uma relação geométrica de dependência entre o deslocamento vertical do centro de massa $(x)$ com o deslocamento vertical da dianteira $(x \mathrm{~d})$ e traseira $(x \mathrm{t})$ do veículo e com deslocamento angular de arfagem do veículo em relação ao centro de massa $(\theta \mathrm{c})$. $\mathrm{Na}$ figura 2 é apresentado o diagrama de corpo livre para o movimento de deslocamento rotacional: 


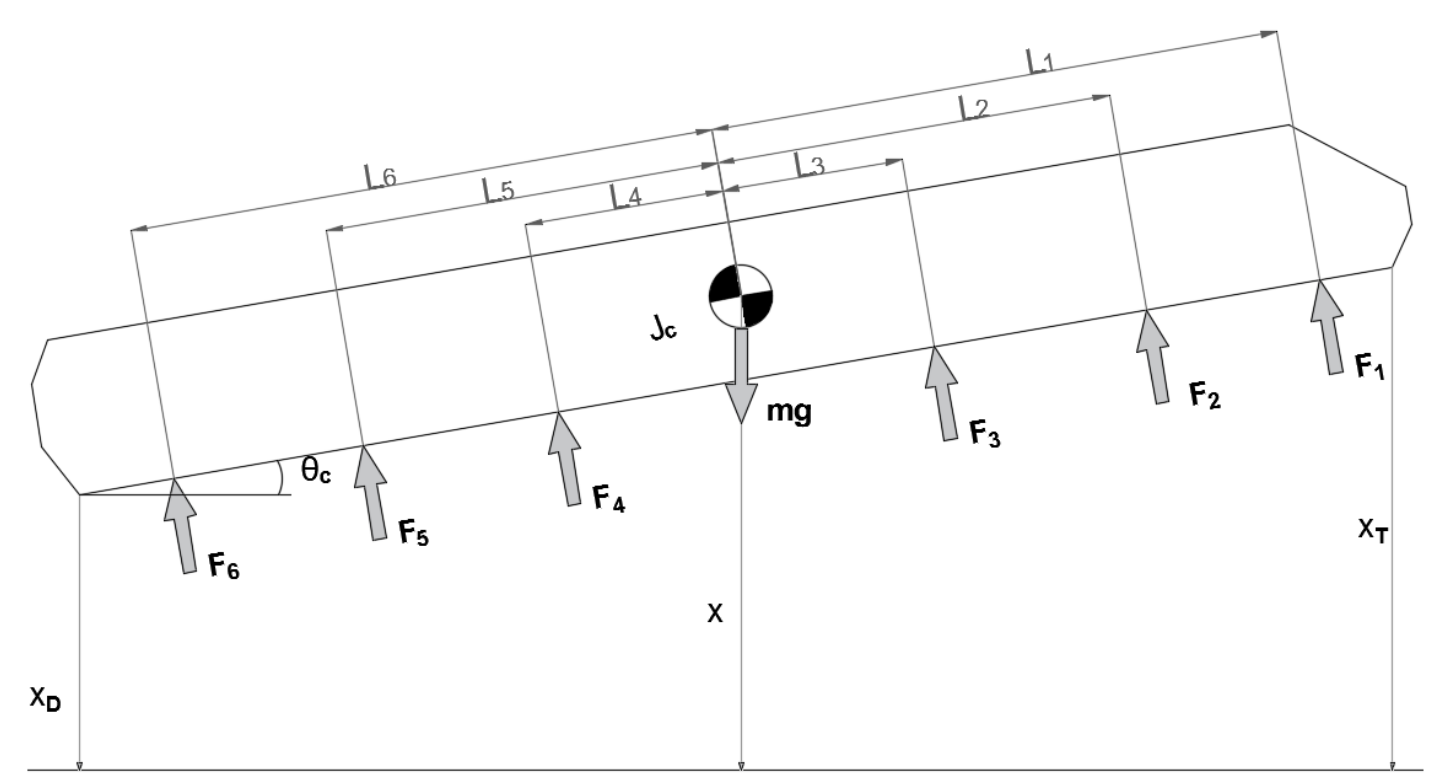

Figura 2 - Diagrama de corpo livre para o movimento de pitch

Consequentemente a equação do movimento vertical da carroceria, para um veículo de esteira de 6 rodas, onde $1 \leq i \leq 6$, é descrita como:

$$
\ddot{z}=-\frac{1}{m}\left(\sum_{1}^{6} F_{i}\right)+g \cos (\alpha)
$$

Onde $m$ é o valor da massa da metade da massa total do veículo, $F_{1}$ à $F_{6}$ são as forças transmitidas pela suspensão, $\ddot{z}$ é a aceleração da massa no sentido vertical, g é a aceleração da gravidade e $\alpha$ é o ângulo da pista. Estas equações somente levam em conta o deslocamento vertical do veículo.

As equações para o movimento de arfagem do casco são desenvolvidas com relação ao eixo vertical e eixo horizontal,

$$
\ddot{\theta}_{c}=-\frac{1}{J_{c}}\left(\sum_{1}^{3} F_{i} L_{i}-\sum_{4}^{6} F_{i} L_{i}-\sum_{1}^{3} F_{A T i} * V_{T i}-\sum_{4}^{6} F_{A T i} * V_{T i}\right)=0
$$

Onde $J_{c}$ é o momento de inércia de massa, $\ddot{\theta}_{c}$ é a aceleração angular, $L_{1}$ à $L_{6}$ são as distâncias horizontais entre o centro de massa e as rodas de rodagem 1 à 6 , respectivamente, e o centro de massa do casco e $V_{T 1}$ à $V_{T 6}$ são as distâncias verticais entre as tangencias das rodas de rodagem 1 à 6 , respectivamente, e o centro de massa do casco.

Desenvolvendo os termos presentes na equação para as forças das molas e amortecedores, obtêm-se:

$$
F_{i}=F_{m i}+F_{a i}
$$


Os valores de $F_{m i}$, que são as forças das molas, e $F_{a i}$, que são as forças dos amortecedores, podem ser obtidos através das seguintes equações:

Para o intervalo $1 \leq i \leq 3$ :

$$
\begin{gathered}
F_{m i}=K_{i}\left(z-z_{i}+L_{i} * \operatorname{sen}(\theta)\right) \\
F_{a i}=C_{i}\left(\dot{z}-\dot{z}_{l}+L_{i} * \dot{\theta} * \cos (\theta)\right)
\end{gathered}
$$

Para o intervalo $4 \leq i \leq 6$ :

$$
\begin{gathered}
F_{m i}=K_{i}\left(z-z_{i}-L_{i} * \operatorname{sen}(\theta)\right) \\
F_{a i}=C_{i}\left(\dot{z}-\dot{z}_{l}-L_{i} * \dot{\theta} * \cos (\theta)\right)
\end{gathered}
$$

No equacionamento anterior têm-se as forças de mola, $F_{m 1}$ à $F_{m 6}$, da roda 1 à 6 respectivamente, bem como as força dos amortecedores $F_{a 1}$ à $F_{a 6} . K_{1}$ à $K_{6}$ são as constantes de rigidez das molas e $C_{1}$ à $C_{6}$ são as constantes de amortecimento. As deflexões são obtidas pelo somatório de todos os deslocamentos dos componentes, sendo $z$ o deslocamento vertical da massa do veículo, $z_{1}$ à $z_{6}$ deslocamentos das rodas, $L_{1} * \operatorname{sen}(\theta)$ à $L_{6} * \operatorname{sen}(\theta)$ referente a inclinação da carroceria no movimento de arfagem. No caso das forças de amortecimento estes itens contam com um ponto na parte superior e referem-se as derivadas destes deslocamentos, ou seja, suas velocidades.

Para os momentos em relação ao eixo vertical as distâncias $V_{T 1}$ à $V_{T 6}$ podem ser modeladas da mesma forma que as deflexões das molas, pois esta distância depende:

Para o intervalo $1 \leq i \leq 3$ :

$$
V_{T i}=\left(V_{i}+z-z_{i}+L_{i} * \operatorname{sen}(\theta)\right)
$$

Para o intervalo $4 \leq i \leq 6$ :

$$
V_{T i}=\left(V_{i}+z-z_{i}-L_{i} * \operatorname{sen}(\theta)\right)
$$

Sendo $V_{1}$ à $V_{6}$ é a distância estática entre o centro de massa e o solo de cada uma das rodas. As forças que atuam na interação da esteira com o solo, horizontalmente, (sentido longitudinal), podem ser representadas:

$$
F_{a t i}=F_{S i} * \mu
$$

Aqui $F_{a t 1}$ à $F_{a t 6}$ se referem as forças de atrito que cada roda sofre, as quais dependem das forças normais, $F_{S 1}$ à $F_{S 6}$, desenvolvidas na interação esteira - rodas - solo e o coeficiente de atrito, $\mu$, da interação esteira - solo. Esse coeficiente de atrito é o termo que leva em conta o tipo de interação que a esteira sofrerá. Já as forças normais das rodas, $F_{S i}$, são desenvolvidas da seguinte forma: 


$$
F_{S i}=K_{R i}\left(z_{i}(t)-z_{i}(t+\Delta t)\right)
$$

Até o momento foram desenvolvidas as equações aplicadas a qualquer veículo multirrodas modelado bidimensionalmente. Os efeitos da esteira são modelados como molas verticais lineares exercendo uma força de restauração para alinhar as rodas de rodagem, proporcional ao deslocamento relativo entre essas rodas. Ou seja, quando as rodas estiverem alinhadas no mesmo eixo horizontal, não haverá forças de contribuição devido a tensão da esteira. A figura 3, mostra graficamente o modelo utilizado para a análise da esteira.
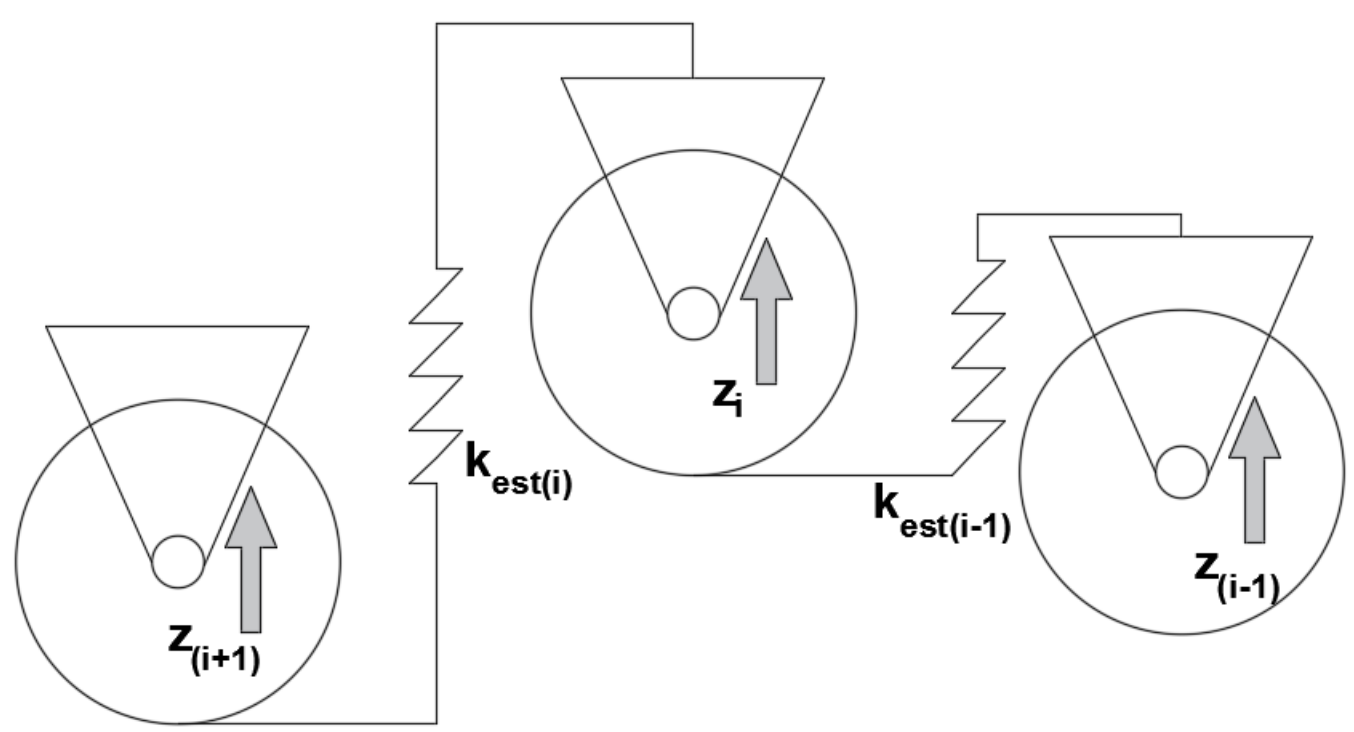

Figura 3 - Modelo de tensão da esteira para os segmentos intermediários.

Matematicamente esse efeito da tensão da esteira pode ser obtido através da equação 12 , onde $T_{t}$ é a tensão da esteira, $k_{\text {est } 1}$ à $k_{\text {est }}$ a rigidez da esteira entre as rodas de rodagem, $k_{e s t 0}$ e $z_{0}$ a rigidez e o deslocamento, respectivamente, da porção frontal inclinada da esteira e $k_{e s t}$ e $z_{7}$ a rigidez e o deslocamento, respectivamente, da porção traseira inclinada da esteira. Esses deslocamentos $z_{0}$ e $z_{6}$ dependerão da altura do obstáculo que o veículo irá transpor. A variável $T$ diz respeito a pré-tensão aplicada inicialmente a esteira. Quanto maior for seu valor, maior também deverá ser a rigidez da esteira, consequentemente.

$$
T_{t}=-k_{e s t i} *\left(z_{(i+1)}-z_{i}\right)+k_{e s t(i-1)} *\left(z_{i}-z_{(i-1)}\right)+T
$$

Tendo definido todos os termos, e como será avaliado o comportamento da esteira através dos deslocamentos relativos das rodas, são apresentadas as equações dinâmicas dos graus de liberdade destas rodas a partir do diagrama de corpo livre da figura 4 , da seguinte forma: 


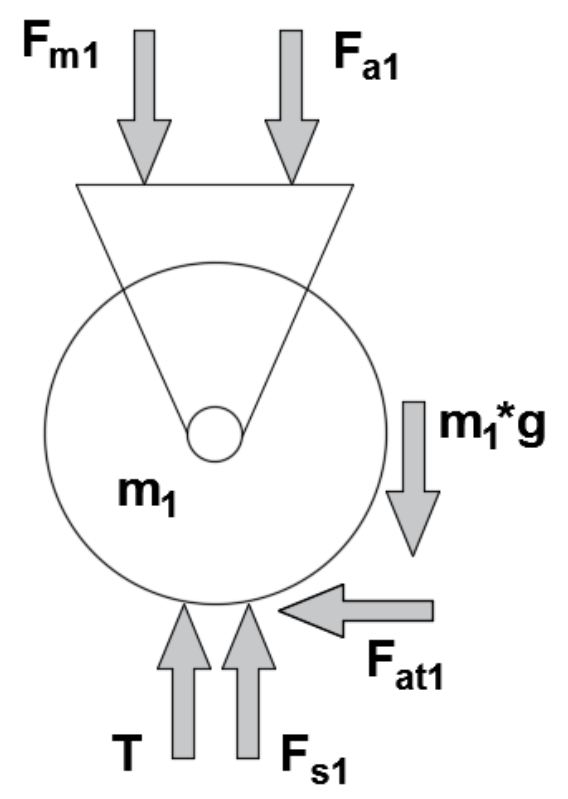

Figura 4 - Diagrama de corpo livre da roda 1.

$$
\begin{gathered}
\ddot{z}_{\iota}=\frac{1}{m_{i}}\left(F_{i}-F_{S i}+k_{e s t i} *\left(z_{(i+1)}-z_{i}\right)-k_{e s t(i-1)}\right. \\
\left.\quad *\left(z_{i}-z_{(i-1)}\right)-T\right)+g \cos (\alpha)
\end{gathered}
$$

Aqui a aceleração de cada uma das massas não suspensas é encontrada, onde $m_{1}$ à $m_{6}$ representa cada uma dessas massas. Os outros termos foram definidos anteriormente e representam cada uma das forças presentes.

\subsection{Modelo numérico}

Um programa foi desenvolvido visando à solução simultânea das equações. Este é utilizado para avaliar o comportamento dinâmico de um veículo de esteira com 6 rodas, modelado bidimensionalmente, transpondo obstáculos com diferentes níveis de agressividade.

O desenvolvimento do programa é baseado no sistema de equações diferenciais, isolando-se as acelerações e calculando as mesmas de forma iterativa, feito através de um diagrama de blocos, montado no programa comercial Matlab Simulink. Calculada as acelerações, usam-se dois passos consecutivos de integração numérica que permite o cálculo das velocidades e deslocamentos, para um dado instante no tempo. Esses dados são usados como condições iniciais para os cálculos do próximo instante de tempo, formando um laço iterativo até o fim do período de simulação.

Os dados de entrada para a resolução do sistema de equações diferenciais são os sinais da amplitude do terreno no tempo. No programa, assim como no sistema de equações, os sinais de terreno são representados por $Z(t)$. Para a parte traseira do veículo utilizase uma função de atraso, (delay), para atrasar esse sinal de terreno em um determinado intervalo de tempo, definido como $(t+\Delta t)$, referente à distância entre eixos do veículo, fazendo com que as rodas traseiras recebam o mesmo sinal que as dianteiras, com um atraso de $\Delta t$. 
Para definir os parâmetros de entrada do programa utiliza-se uma lista de dados conhecidos do veículo, que são declarados no modelo como constantes, e cada um desses, associado a um ou mais blocos no diagrama de blocos da equação. Esses dados são valores associados aos blocos de ganho além dos vetores de entrada do terreno e do tempo.

\section{METODOLOGIA}

2.1. Parâmetros do veículo utilizado

O veículo de esteira escolhido para o desenvolvimento das análises é o M60, figura 5. Esse veículo teve sua produção entre os anos de 1960 e 1987 em uma parceria das forças armadas americanas com a Chrysler. A escolha desse veículo militar se deve por contar com desenvolvimentos anteriores, utilizados para validação do modelo numérico, bem como possuir os parâmetros que serão inseridos no programa para a análise.

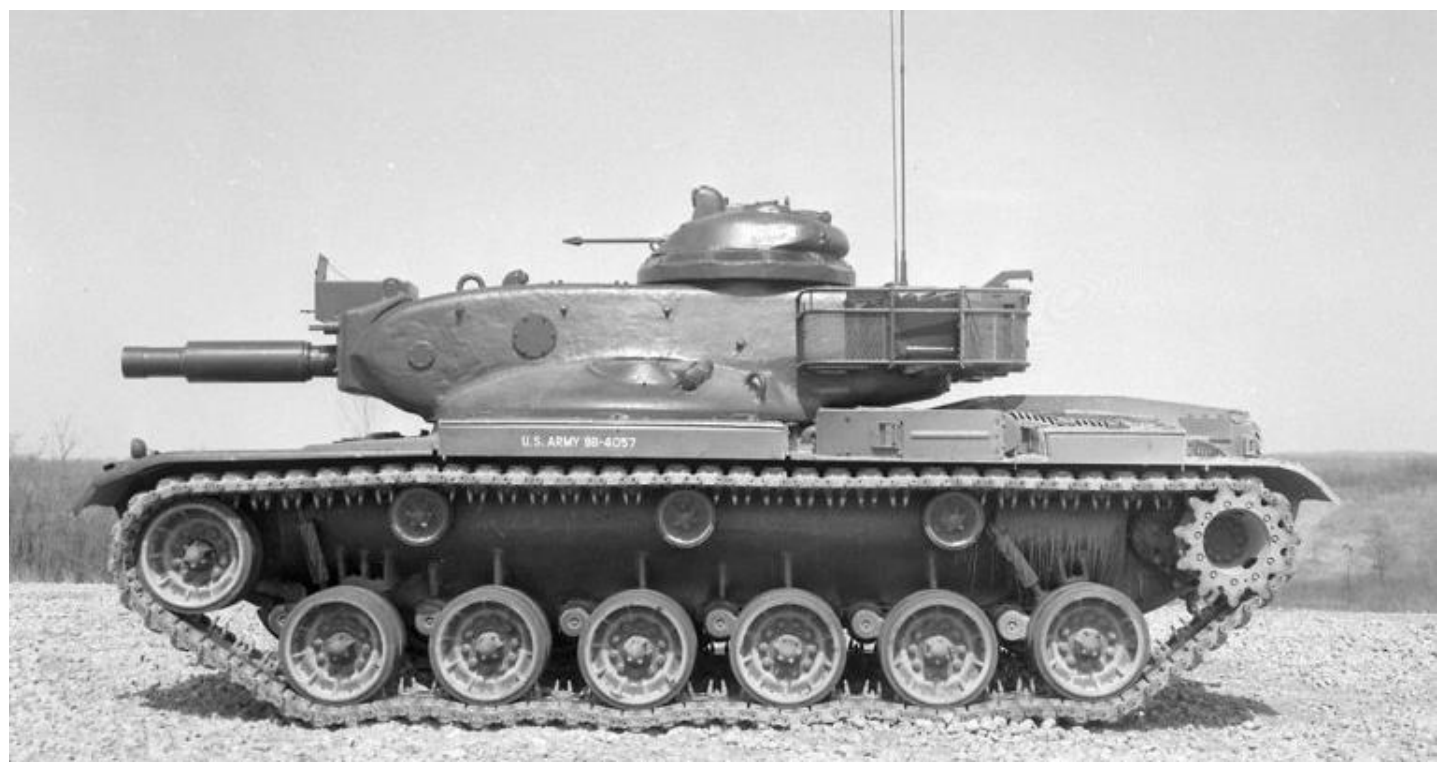

Figura 5 - Veículo militar de esteira M60.

$\mathrm{m}$ - Massa de meio veículo $(\mathrm{kg})$ 25000

$J_{c}-$ Momento de Inércia $\left(\mathrm{kg}^{*} \mathrm{~m}^{2}\right)$ 65723

$\mathrm{m}_{\mathrm{i}}$ - Massa de cada roda $(\mathrm{kg})$ .644

$\mathrm{L}_{1}$ - Distância entre roda 1 e centro de massa (m) 1.93

$\mathrm{L}_{2}$ - Distância entre roda 2 e centro de massa (m) 1.12

$\mathrm{L}_{3}$ - Distância entre roda 3 e centro de massa $(\mathrm{m})$......................................... 0.30

$\mathrm{L}_{4}$ - Distância entre roda 4 e centro de massa $(\mathrm{m})$..........................................6.61

$\mathrm{L}_{5}$ - Distância entre roda 5 e centro de massa $(\mathrm{m})$............................................42

$\mathrm{L}_{6}$ - Distância entre roda 6 e centro de massa $(\mathrm{m})$....................................2.24

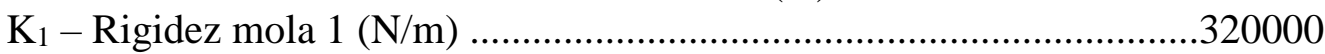

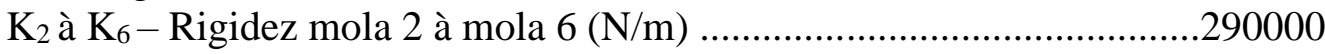

$\mathrm{K}_{\text {est1 }}$ à $\mathrm{K}_{\text {est5 }}$ - Rigidez molas lineares esteira $(\mathrm{N} / \mathrm{m})$................................65672

$\mathrm{K}_{\text {est } 0}$ e $\mathrm{K}_{\text {est6 }}$ - Rigidez molas lineares esteira $(\mathrm{N} / \mathrm{m})$...............................107000 
$\mathrm{K}_{\mathrm{r} 1}$ à $\mathrm{K}_{\mathrm{r} 6}-$ Rigidez rodas $(\mathrm{N} / \mathrm{m})$

$\mathrm{v}$ - Altura estática rodas ao centro de massa (m)

$\mathrm{C}_{1}$ à $\mathrm{C}_{6}-$ Coeficiente de amortecimento $(\mathrm{Ns} / \mathrm{m})$

\subsection{Dados complementares}

Para o desenvolvimento das análises da mesma forma que observado na literatura, percebeu-se que em baixas velocidades são mais pronunciadas as diferenças das respostas dinâmicas na comparação de veículos de esteira com veículos multirrodas. A partir desses dados, utilizou-se duas velocidades para o desenvolvimento das análises dinâmicas, $18 \mathrm{~km} / \mathrm{h}$ e $36 \mathrm{~km} / \mathrm{h}$, o que resulta em $5 \mathrm{~m} / \mathrm{s}$ e $10 \mathrm{~m} / \mathrm{s}$ respectivamente.

Os obstáculos também foram selecionados de acordo com a literatura, onde se pode perceber que as esteiras demonstram um grande diferencial em terrenos mais acidentados, tendo em terrenos mais suaves respostas bastante aproximadas a veículos multirrodas. Serão tratados nesse trabalho obstáculos sobre terrenos rígidos, com formato quadrado com $0,2 \mathrm{~m}$ e $0,46 \mathrm{~m}$.

Esse tipo de obstáculo tem grande importância na análise dinâmica pois pode induzir efeitos de vibração, choque e imobilização total, dependendo da velocidade, relação entre o tamanho do obstáculo e o tamanho do veículo, e o espaçamento, bem como, verificar o comportamento dinâmico em situações menos complexas, facilitando a interpretação da coerência dos resultados.

\section{RESULTADOS}

A partir das análises realizadas para cada obstáculo e velocidade do veículo, foram obtidos os históricos temporais para deslocamentos, velocidades e as acelerações translacionais e rotacionais do centro de massa das massas suspensa e não suspensas do veículo, os quais são demonstrados nas figuras 6 a 17. Com a metodologia proposta, aspectos relativos à estabilidade e conforto do veículo podem ser retirados desses resultados. 


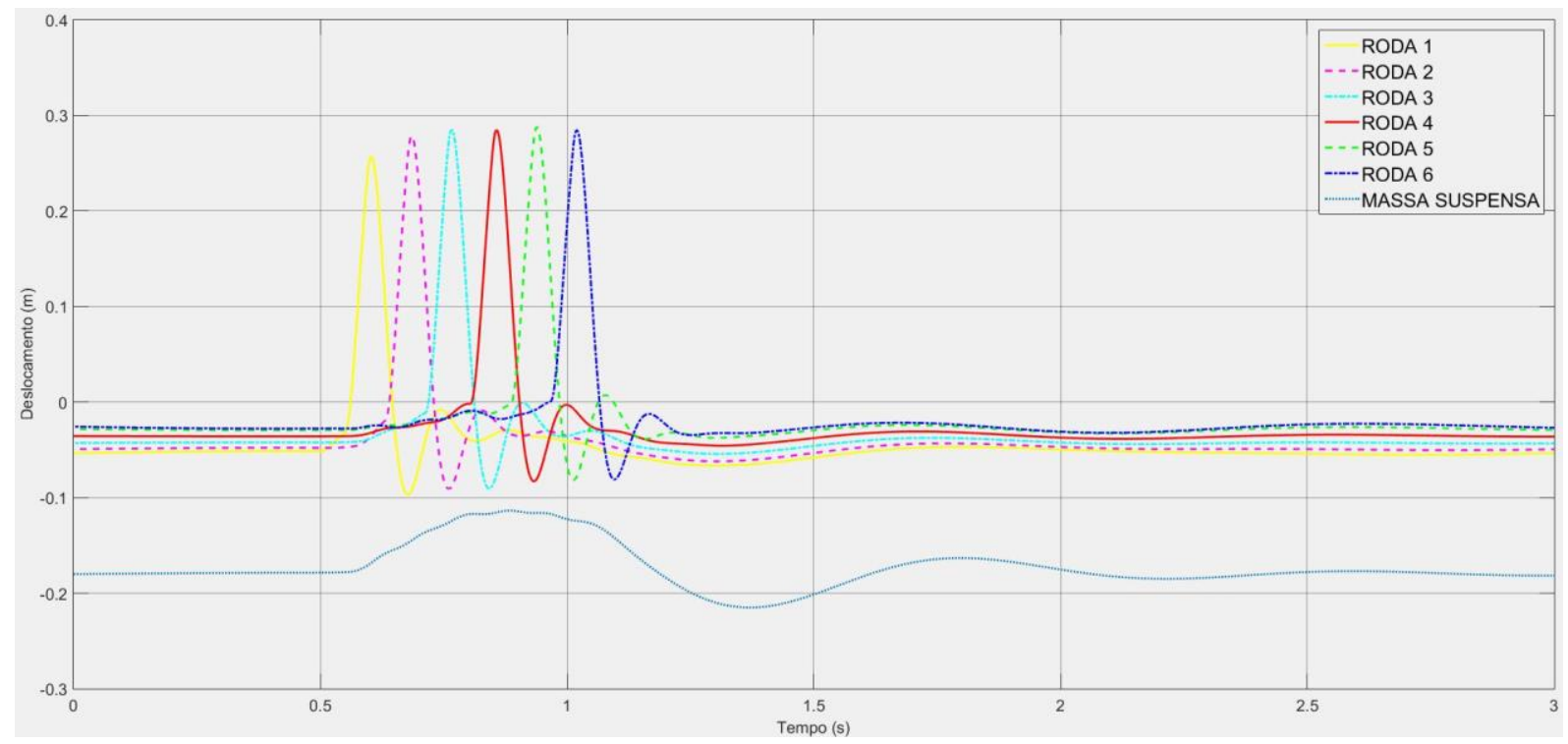

Figura 6 - Resposta dinâmica de deslocamento das massas suspensas e não suspensas velocidade $10 \mathrm{~m} / \mathrm{s}$ - obstáculo $0,46 \mathrm{~m}$.

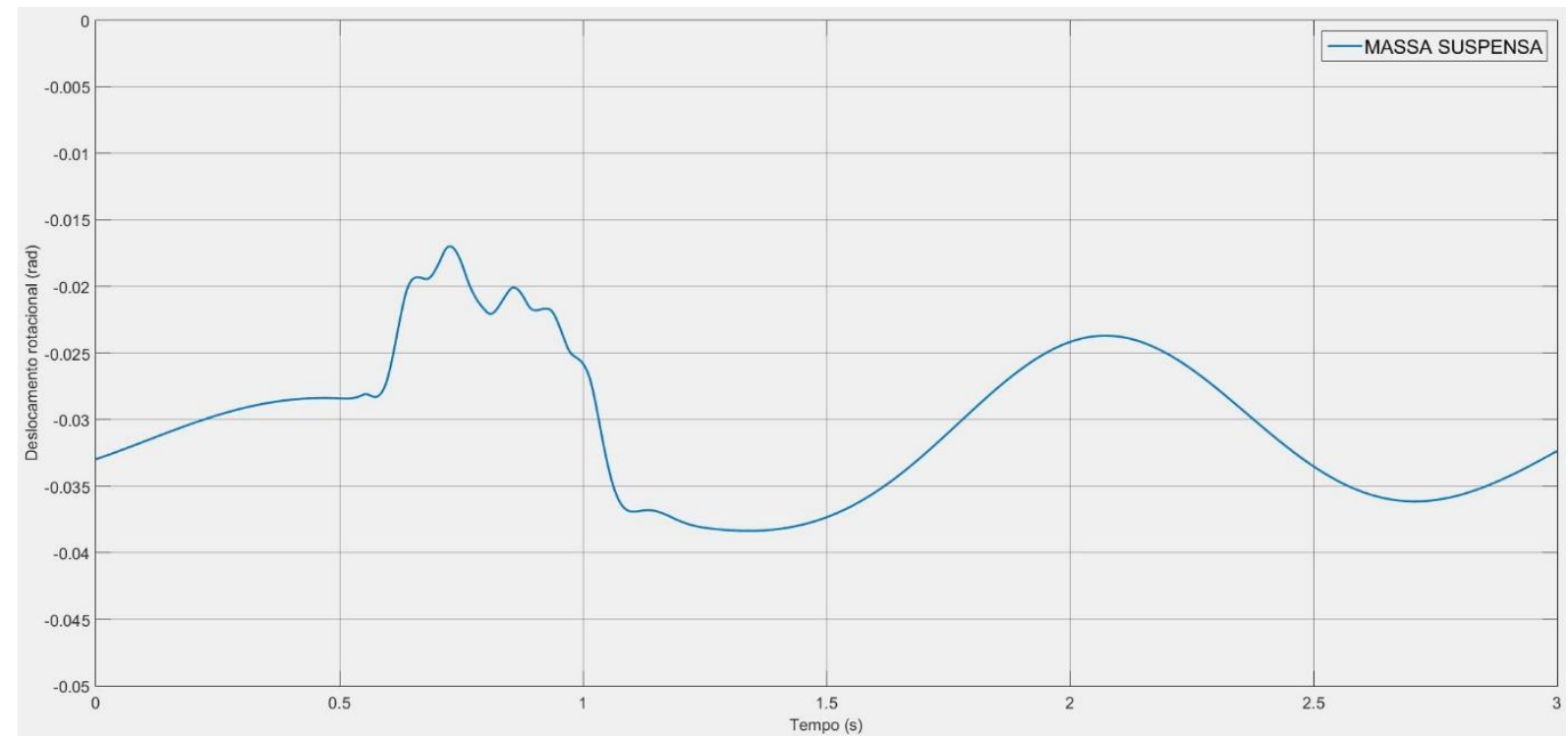

Figura 7 - Resposta dinâmica de deslocamento rotacional da massa suspensa - velocidade $10 \mathrm{~m} / \mathrm{s}$ - obstáculo $0,46 \mathrm{~m}$. 


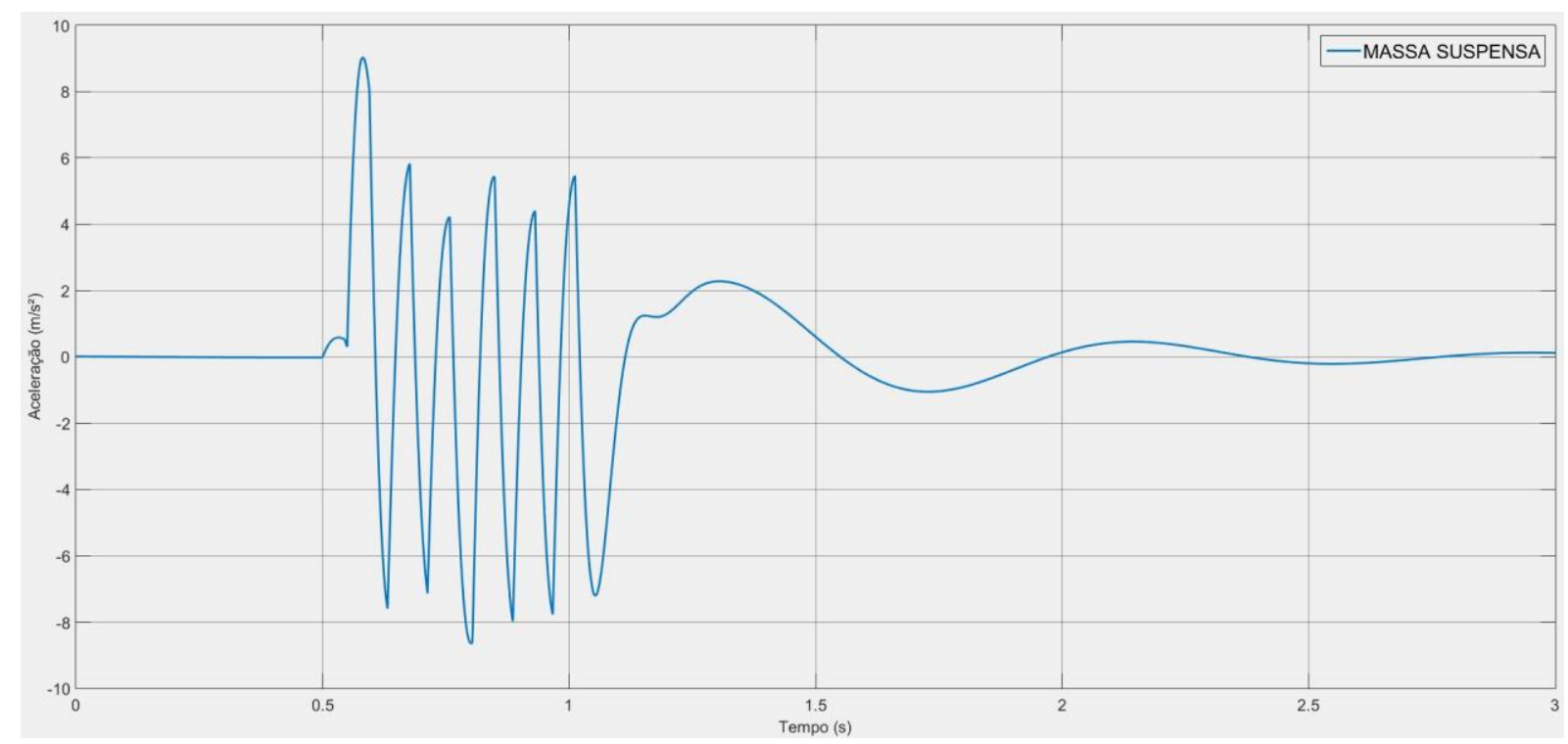

Figura 8 - Resposta dinâmica de aceleração da massa suspensa - velocidade $10 \mathrm{~m} / \mathrm{s}$ - obstáculo $0,46 \mathrm{~m}$.

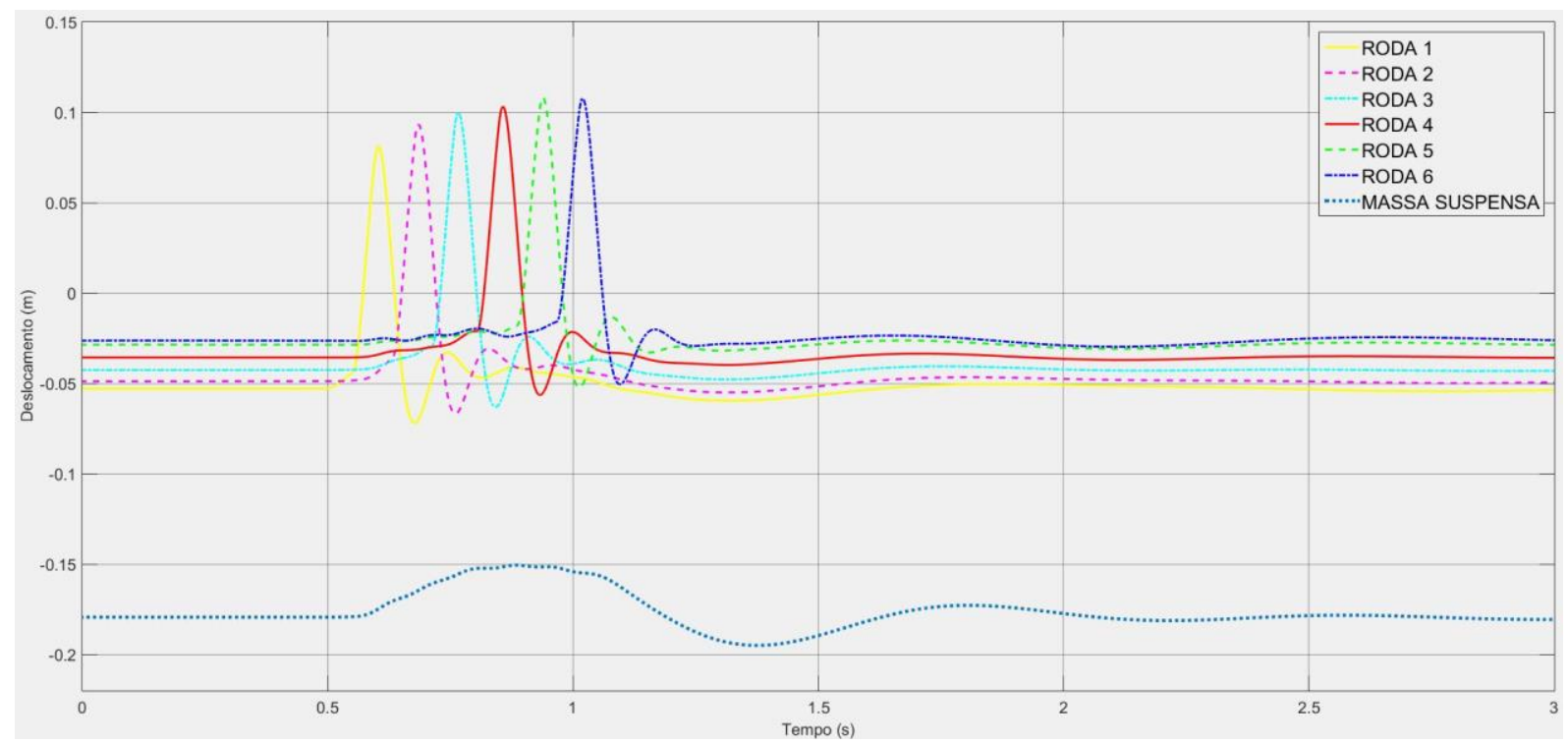

Figura 9 - Resposta dinâmica de deslocamento das massas suspensas e não suspensas velocidade $10 \mathrm{~m} / \mathrm{s}$ - obstáculo $0,20 \mathrm{~m}$. 


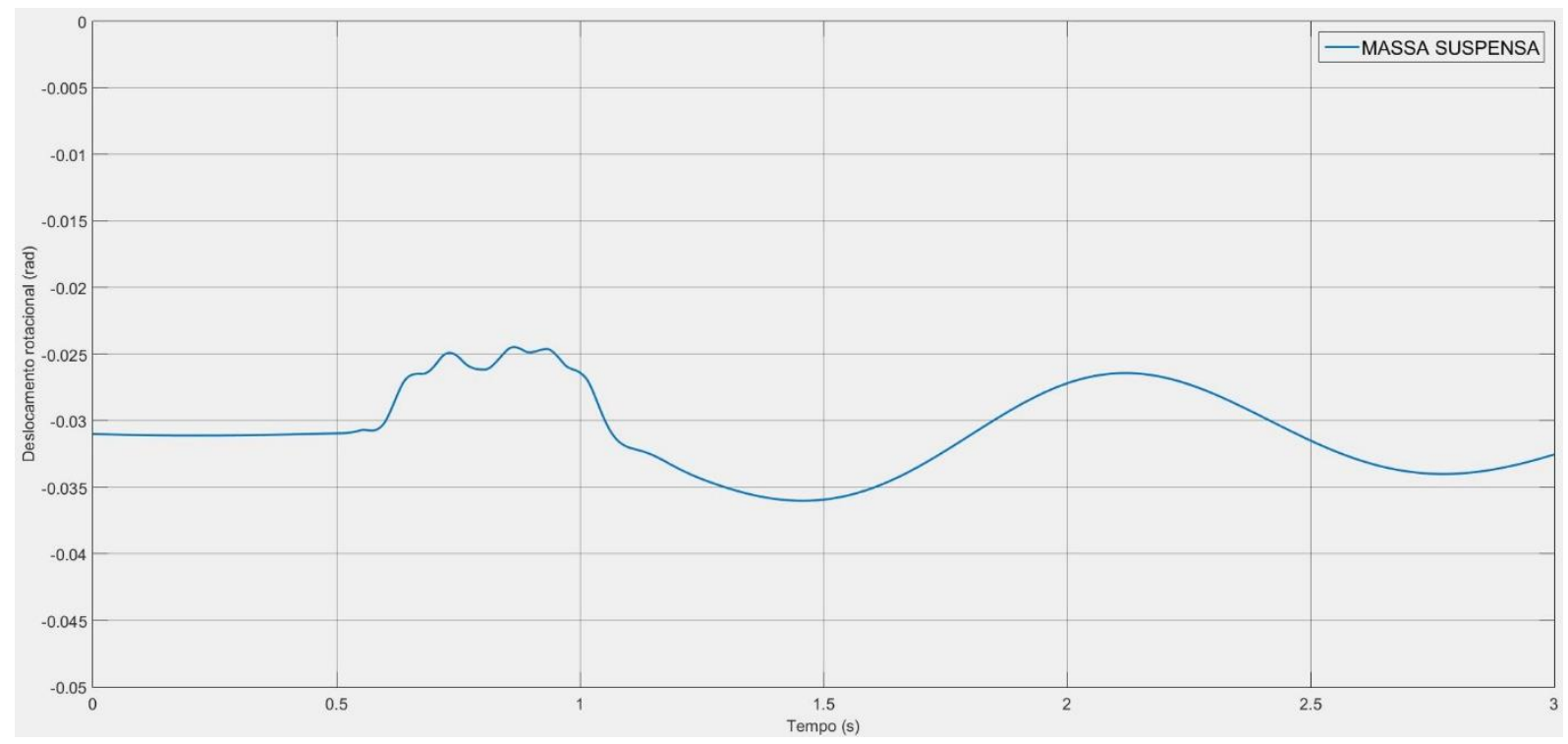

Figura 10 - Resposta dinâmica de deslocamento rotacional da massa suspensa - velocidade $10 \mathrm{~m} / \mathrm{s}$ - obstáculo $0,20 \mathrm{~m}$.

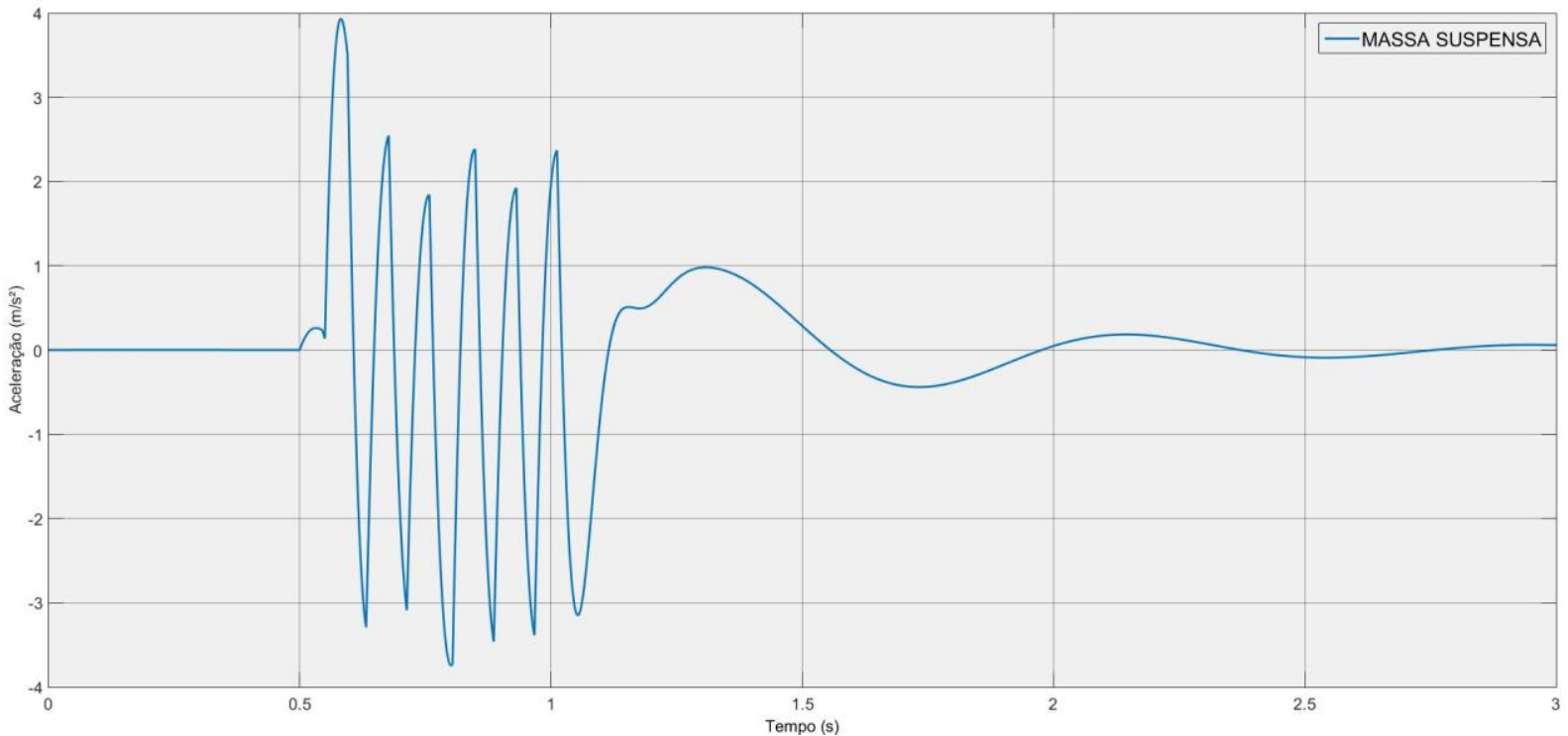

Figura 11 - Resposta dinâmica de aceleração da massa suspensa - velocidade $10 \mathrm{~m} / \mathrm{s}$ obstáculo $0,20 \mathrm{~m}$. 


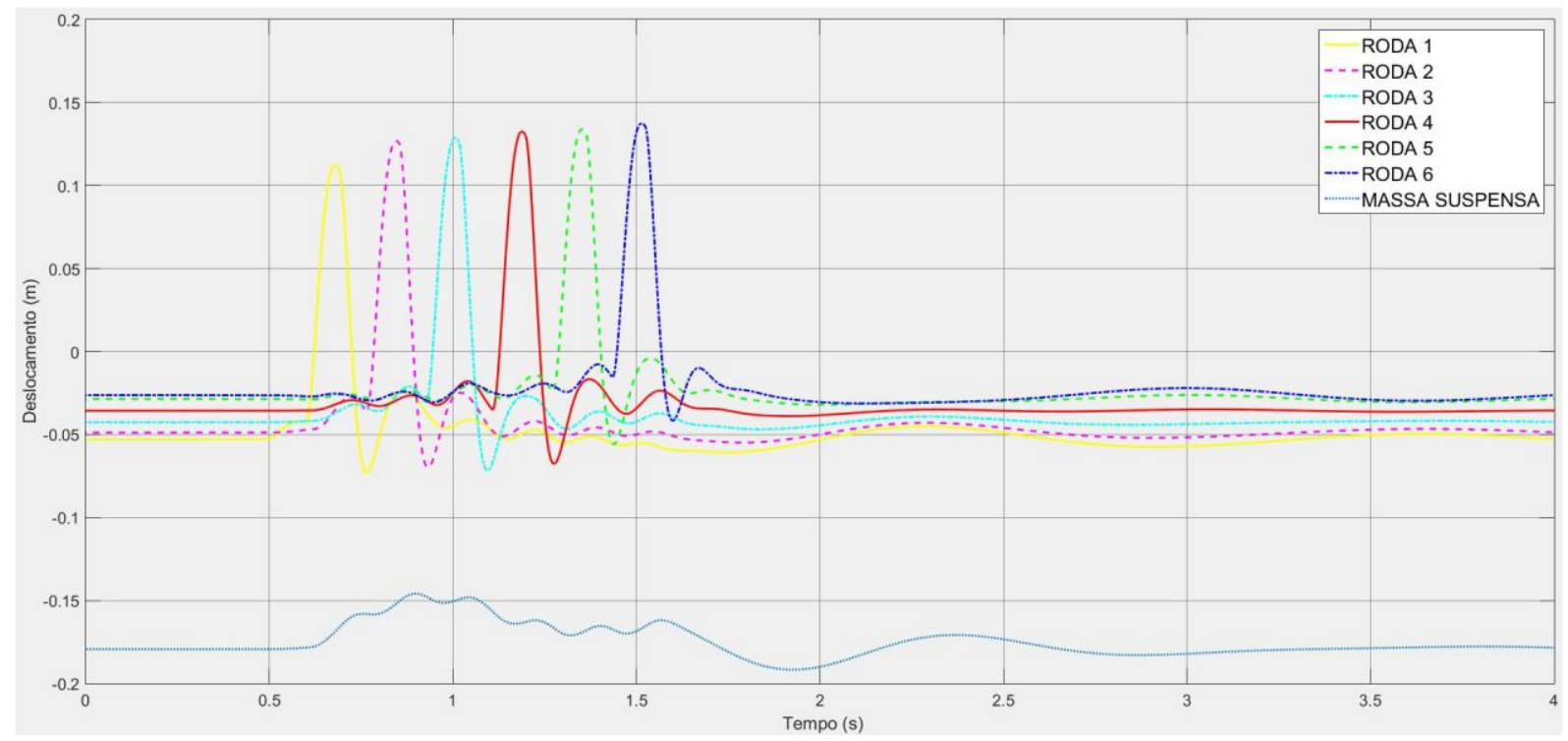

Figura 12 - Resposta dinâmica de deslocamento das massas suspensas e não suspensas velocidade $5 \mathrm{~m} / \mathrm{s}$ - obstáculo $0,20 \mathrm{~m}$.

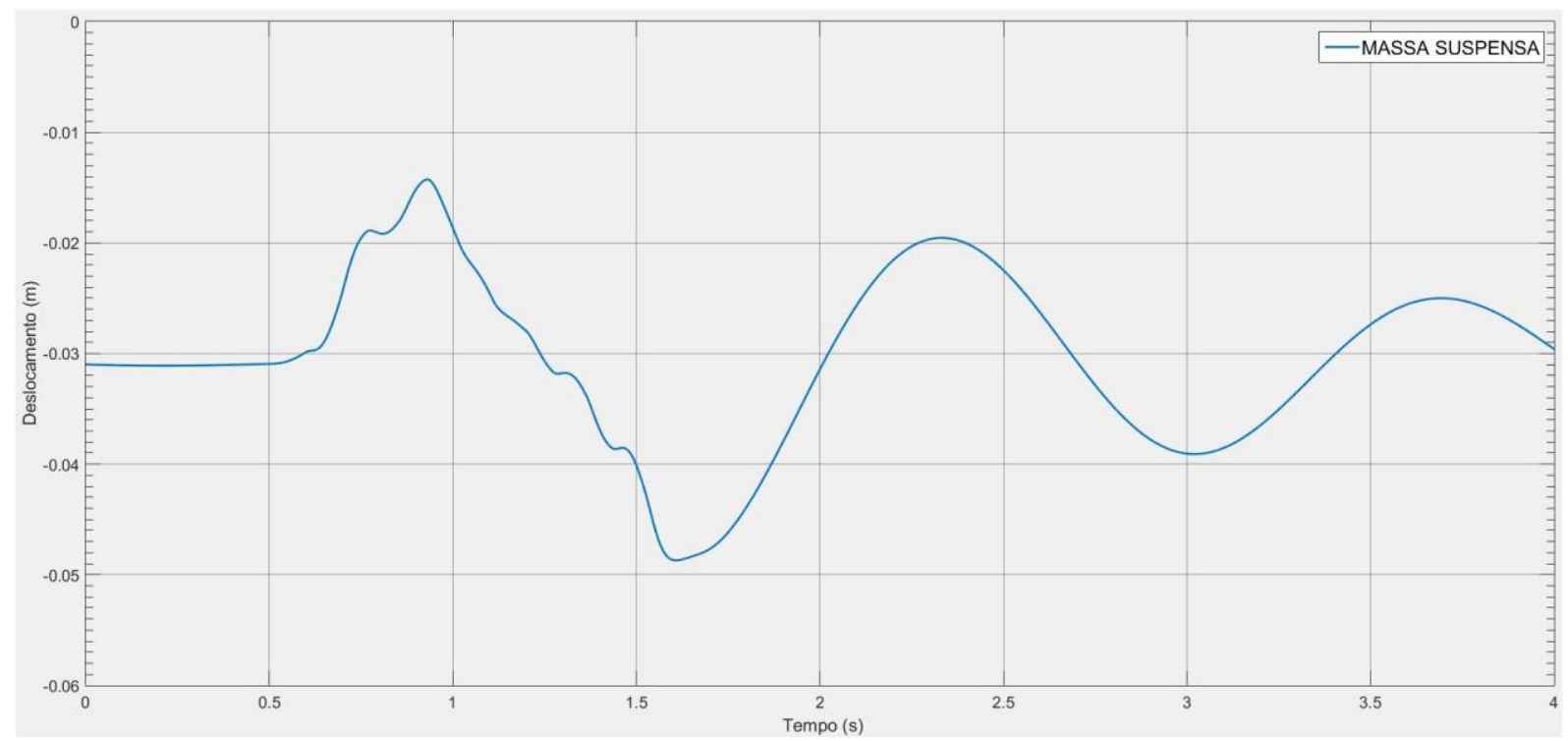

Figura 13 - Resposta dinâmica de deslocamento rotacional da massa suspensa - velocidade $5 \mathrm{~m} / \mathrm{s}$ - obstáculo $0,20 \mathrm{~m}$. 


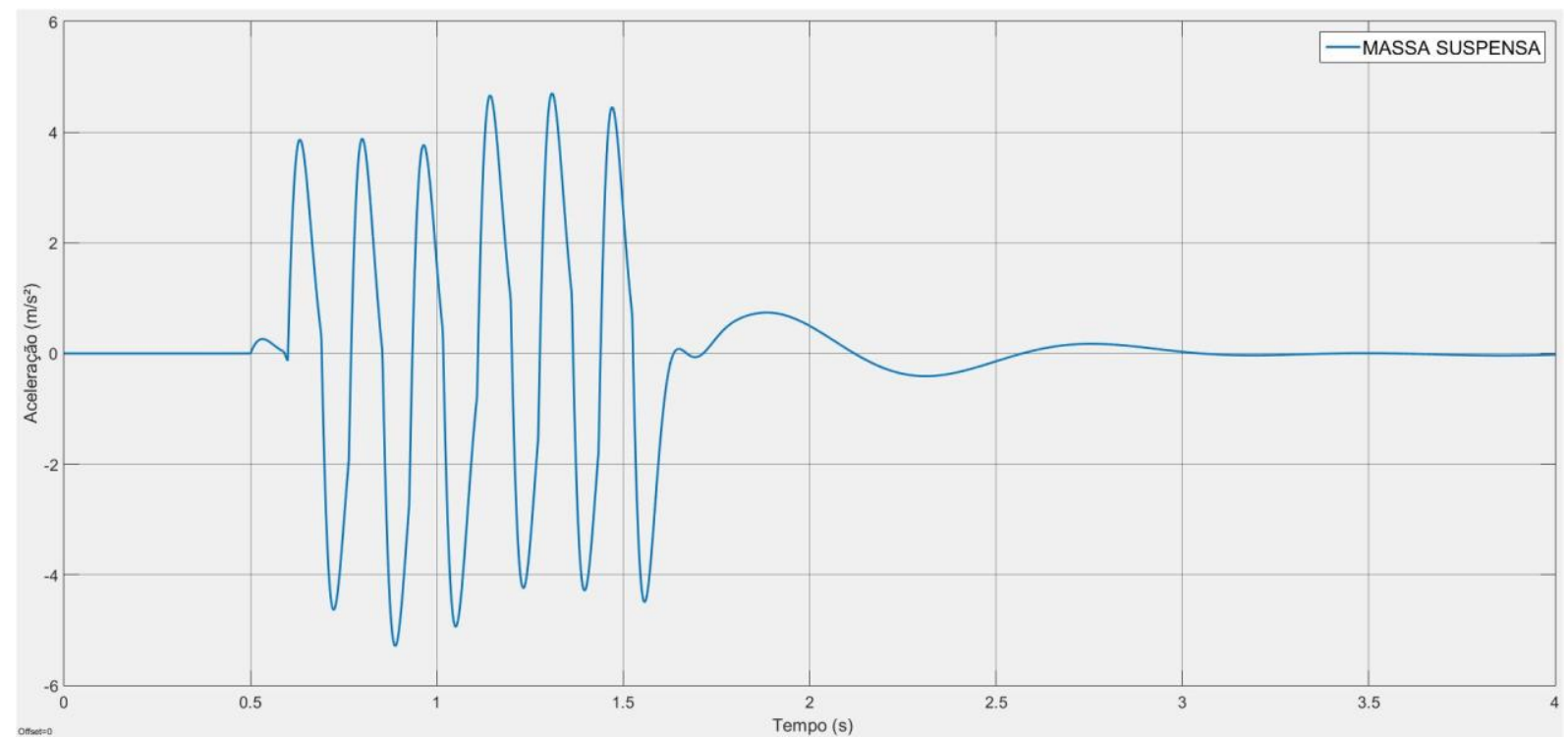

Figura 14 - Resposta dinâmica de aceleração da massa suspensa - velocidade $5 \mathrm{~m} / \mathrm{s}$ - obstáculo $0,20 \mathrm{~m}$.

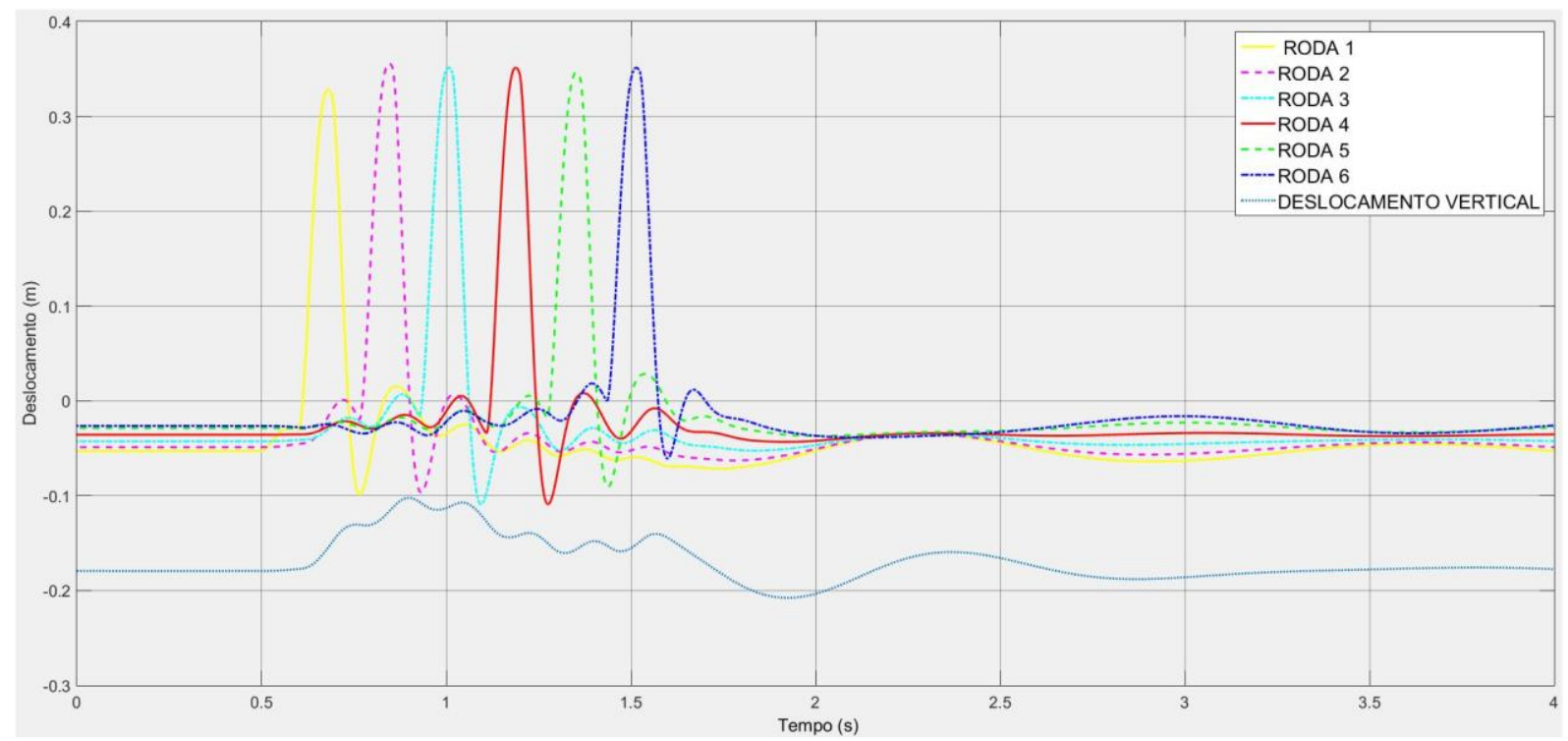

Figura 15 - Resposta dinâmica de deslocamento das massas suspensas e não suspensas velocidade $5 \mathrm{~m} / \mathrm{s}$ - obstáculo $0,46 \mathrm{~m}$. 


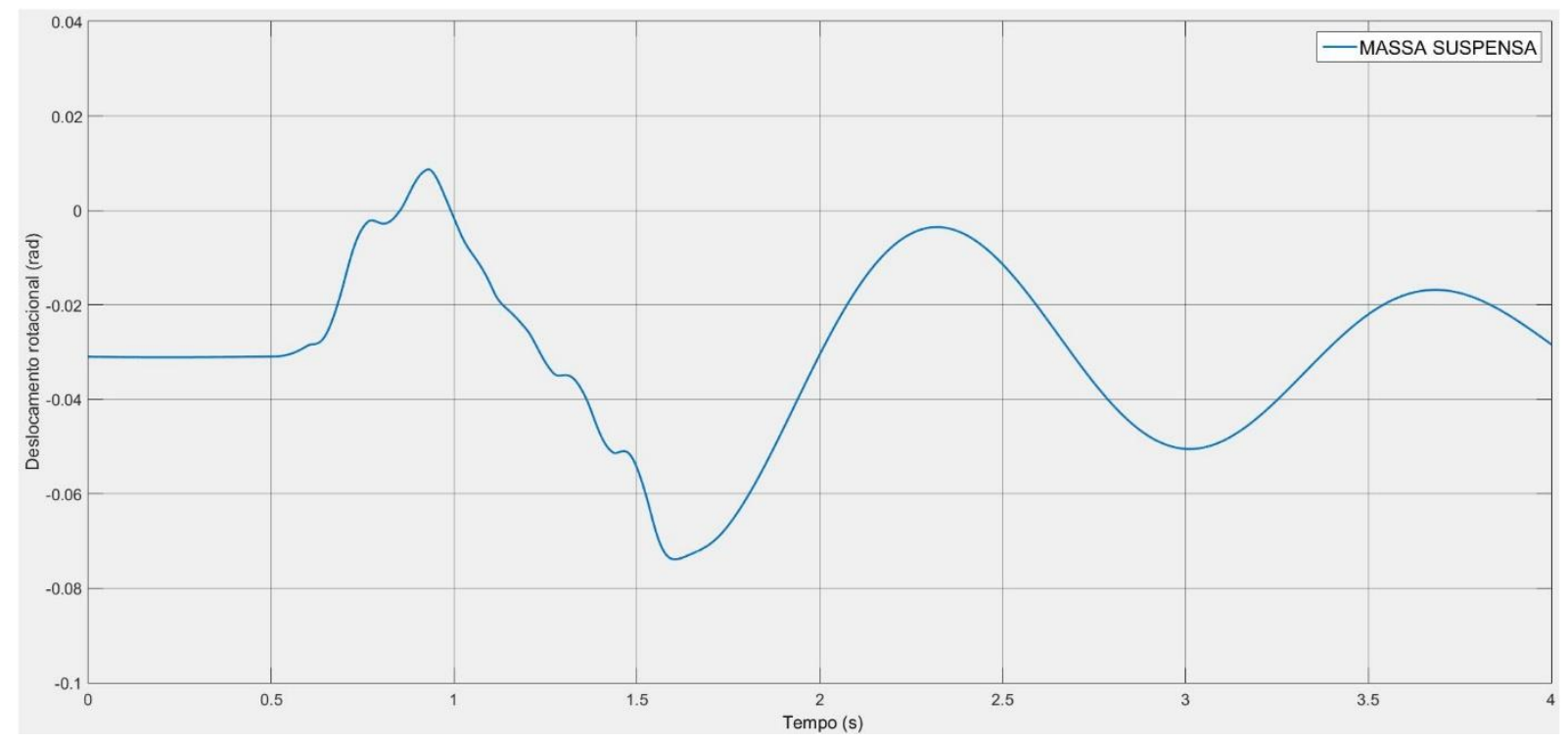

Figura 16 - Resposta dinâmica de deslocamento rotacional da massa suspensa - velocidade $5 \mathrm{~m} / \mathrm{s}$ - obstáculo $0,46 \mathrm{~m}$.

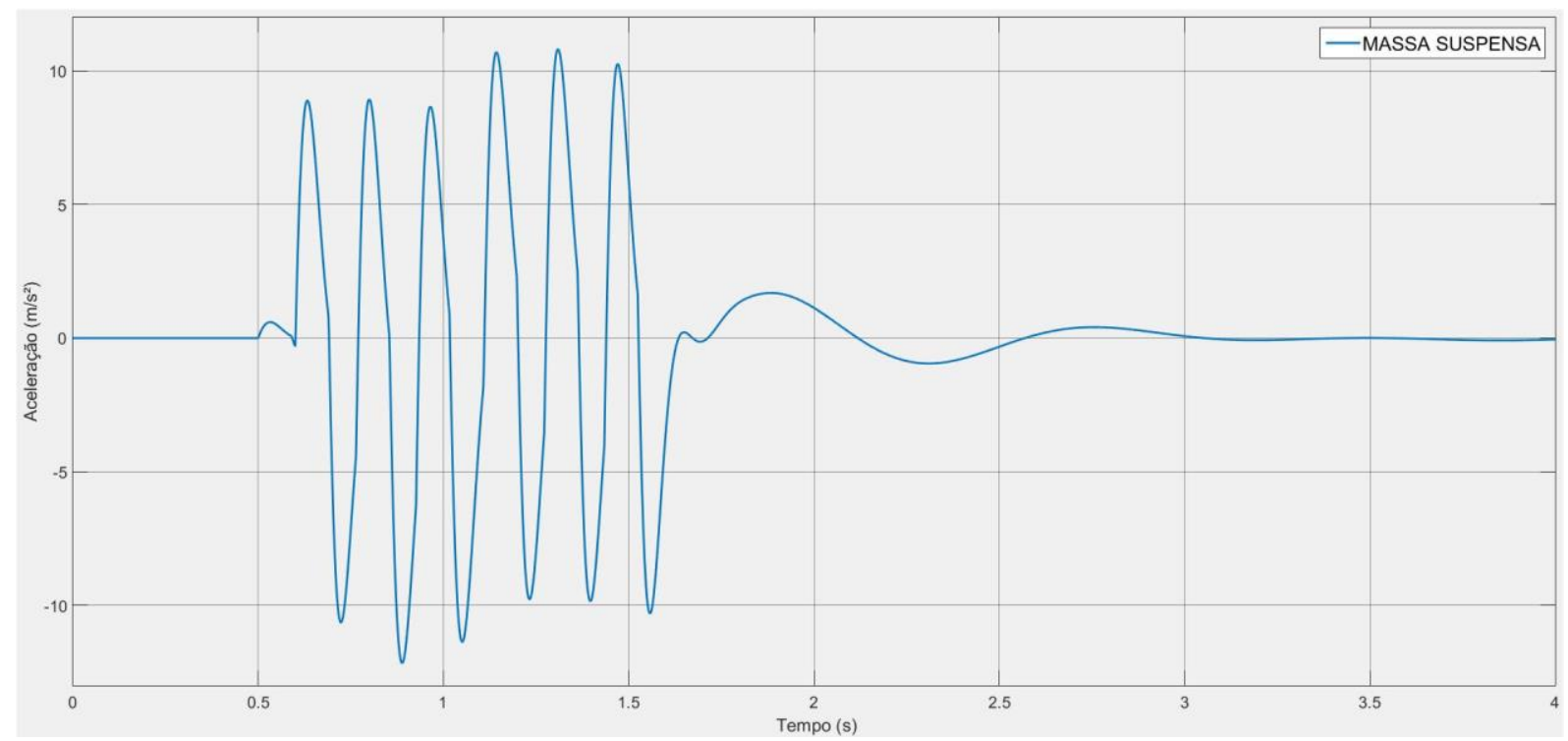

Figura 17 - Resposta dinâmica de aceleração da massa suspensa - velocidade $5 \mathrm{~m} / \mathrm{s}$ - obstáculo $0,46 \mathrm{~m}$.

Podem ser observadas através das respostas que cada roda sofre um pequeno impulso anterior a suas passagem pelo obstáculo. Isso se dá através da corrente, conforme mencionado anteriormente, devido ao modelo matemático utilizado para representá-la. Ele leva em conta os deslocamentos das rodas das adjacências, o que induz um deslocamento nessas rodas, anterior a passagem das mesmas pelo obstáculo, que é o que ocorre no problema real.

Como esperado, os delocamentos verticais e angulares das massas suspensas são mais afetado em velocidades menores com maiores obstáculos. Nessa situação percebe-se que a esteira é benefica, reduzindo os deslocamentos, se comparado a veículos multirrodas. 
Nas acelerações, conforme a literatura já previa, os maiores picos se dão em velocidades menores com grandes obstáculos, como demonstrado nas figuras de resposta dinâmica de aceleração.

\section{CONCLUSÕES}

A metodologia proposta mostra-se bastante eficaz para avaliações preliminares no comportamento geral do veículo. Percebe-se que obstáculos discretos rígidos afetam a performance do veículo demonstrando respostas de acelerações e deslocamentos com valores elevados. Esses picos de deslocamentos e acelerações dependem é claro da velocidade a que o veículo se desloca, as características da suspensão veicular e o tamanho do obstáculo.

Quanto as esteiras, percebe-se que as mesmas trabalham para, além de serem um mecanismo mais eficaz na tração do veículo devido a menor pressão exercida no solo pela maior área de contato, também distribuir os carregamentos nas rodas próximas ao ponto de deslocamento. $\mathrm{Ou}$ seja, as esteiras tornam mais suave o deslocamento das rodas. Essa suavização faz com que os picos de deslocamentos, quando em contato com os obstáculos, sejam menores e o movimento de arfagem seja mais rapidamente dissipado, diferente do que ocorre em veículos multirrodas onde o impacto é sentido por cada roda elevando os picos de deslocamento.

Portanto, percebeu-se que a esteira tem grande importância no estudo de dinâmica vertical, principalmente nos casos onde os obstáculos exigem mais do sistema de suspensão, como é o caso dos obstáculos utilizados nesse trabalho.

Assim, além do desenvolvimento das equações dinâmicas, que podem ser estendidas para outras configurações de veículos, implementou-se uma ferramenta de simulação que disponibiliza dados para outras análises como estrutural ou fadiga, fielmente correspondentes aos terrenos empregados. Essas respostas, apesar das aproximações consideradas, simplificam e aceleram o desenvolvimento de um novo produto, barateando os altos custos, tanto de produção quanto de projeto.

Evidentemente, o modelo aqui empregado pode ser acoplado a um algoritmo de otimização a fim de verificar se molas e amortecedores idênticos são uma boa solução para cada função objetivo (arfagem, conforto, estabilidade, etc...), podendo assim obter um veículo mais alinhado as necessidades.

Por fim, através do desenvolvimento desse trabalho, é possível perceber que apesar da dificuldade do equacionamento do modelo matemático do veículo com a esteira e do modelo proposto ser uma simplificação do que ocorre dinamicamente, o mesmo é mais preciso que simplificações utilizadas em alguns desenvolvimentos de outros autores, os quais se assemelham muito a modelos de veículos multirrodas, ou seja, a esteira não é levada em conta na análise dinâmica. 


\section{REFERÊNCIAS BIBLIOGRÁFICAS}

[1] DHIR, A.; SANKAR, S. Analytical track models for ride dynamic simulation of tracked vehicles. Journal of Terramechanics, 1994. pp. 107-138.

[2] GILLESPIE, T. D. Fundamentals of Vehicle Dynamics. [S.l.]: [s.n.], 1992.

[3] LESSEM, A. S.; MURPHY, J. N. R. Studies of the dynamics of tracked vehicles. U. S. Army Material Command. [S.1.]. 1972.

[4] LIANG, Y. et al. Optimal vibration controller design for tracked vehicle half-car suspension systems. Journal of Computational Systems.

[5] RAVISHANKAR, M. K.; SUJATHA, C. Stationary response of a military tracked vehicle. $14^{\circ}$ International Congress on Sounde \& Vibration. Cairns, Australia: [s.n.]. 2007.

[6] WONG, J. Y. Terramechanics and Off-Road Vehicles. Ottawa: Elsevier, 1989.

[7] WONG, J. Y. Theory of ground vehicles. $3^{\text {a }}$. ed. Amsterdam: Copyright by John Wiley \& Sons, 2001.

[8] YAMAKAWA, J.; WATANABE, K. A spatial motion analysis model of tracked vehicles with torsion bar type suspension. Journal of Terramechanics, 113-126, 19 March 2004.

[9] MATLAB for Windows User's Guide. The Math Works Inc. [S.1.]. 1984-2010. 